\title{
Solitary mucosal neuroma of the gingiva without multiple endocrine neoplasia type 2B: a rare case report and literature review
}

\author{
Che Qiu ${ }^{1}$, Lizhen Wang ${ }^{2}$, Huiwen Chen ${ }^{1}$, Zhongchen Song ${ }^{1}$ \\ ${ }^{1}$ Department of Periodontology, Shanghai Ninth People's Hospital, Shanghai Jiao Tong University School of Medicine/College of Stomatology, \\ Shanghai Jiao Tong University/National Center for Stomatology/National Clinical Research Center for Oral Diseases/Shanghai Key Laboratory \\ of Stomatology, Shanghai, China; ${ }^{2}$ Department of Oral Pathology, Shanghai Ninth People's Hospital, Shanghai Jiao Tong University School of \\ Medicine; College of Stomatology, Shanghai Jiao Tong University, Shanghai, China \\ Correspondence to: Zhongchen Song. Department of Periodontology, Shanghai Ninth People's Hospital, Shanghai Jiao Tong University School of \\ Medicine/College of Stomatology, Shanghai Jiao Tong University/National Center for Stomatology/National Clinical Research Center for Oral \\ Diseases/Shanghai Key Laboratory of Stomatology, Shanghai 200011, China. Email: szhongchen@sina.com.
}

\begin{abstract}
Background: Mucosal neuroma $(\mathrm{MN})$ is a benign neural tumor of peripheral nerves histologically characterized by irregular tortuous bundles of nerve cells with prominent perineurium that lie scattered throughout the submucosa. The tumor is usually associated with the multiple endocrine neoplasia type $2 \mathrm{~B}$ (MEN 2B) but rarely occurs without the other components of MEN 2B.

Case Description: A 29-year-old woman presented to our outpatient department with an upper anterior teeth gingiva painless mass for 2-year. Intraoral examination revealed a small, tough, basal wide, well-defined mass in the labial gingival papilla between maxillary central incisor. Excisional biopsy showed that it was characterized by nerve bundles in various sizes surrounded by normal connective tissue in the submucosa under HE staining. Immunohistochemically, the mass showed strongly positive staining of S-100 protein, NSE, NF and weakly positive of EMA. The Laboratory examination and ultrasonography showed no signs of MEN 2B. In the first and second 6 months of follow-up, there was no evidence of recurrence and other components of MEN 2B. The patient was asymptomatic and she is still being followed up every 6 months. Based on these features, the lesion was finally diagnosed as a solitary gingival MN.

Conclusions: In summary, this study showed a rare solitary MN in the gingiva papilla without MEN 2B that has not been reported yet. The histopathological evaluation can be helpful in the differential diagnosis of MN. It is hoped that a greater understanding of solitary MN without MEN 2B in the oral cavity will avoid potential misdiagnosis, and contribute to determining the correct management, which appears to be complete surgical excision with close follow-up for recurrence and other components of MEN 2B surveillance.
\end{abstract}

Keywords: Solitary mucosal neuroma (solitary MN); oral neural tumors; multiple endocrine neoplasia type 2B (MEN 2B); case report; literature review

Received: 19 November 2020; Accepted: 02 July 2021; Published: 10 December 2021.

doi: $10.21037 /$ fomm-20-80

View this article at: https://dx.doi.org/10.21037/fomm-20-80

\section{Introduction}

In 1975, Khairi et al. proposed that the condition of combined medullary thyroid carcinoma (MTC), pheochromocytomas and mucosal neuroma $(\mathrm{MN})$ should be referred to as multiple endocrine neoplasia (MEN) type 3, also known as multiple endocrine neoplasia type 2B (MEN 2B) now. MEN 2B is an autosomal dominant syndrome associated with RET gene mutations and characterized by an aggressive form of MTC and bilateral 

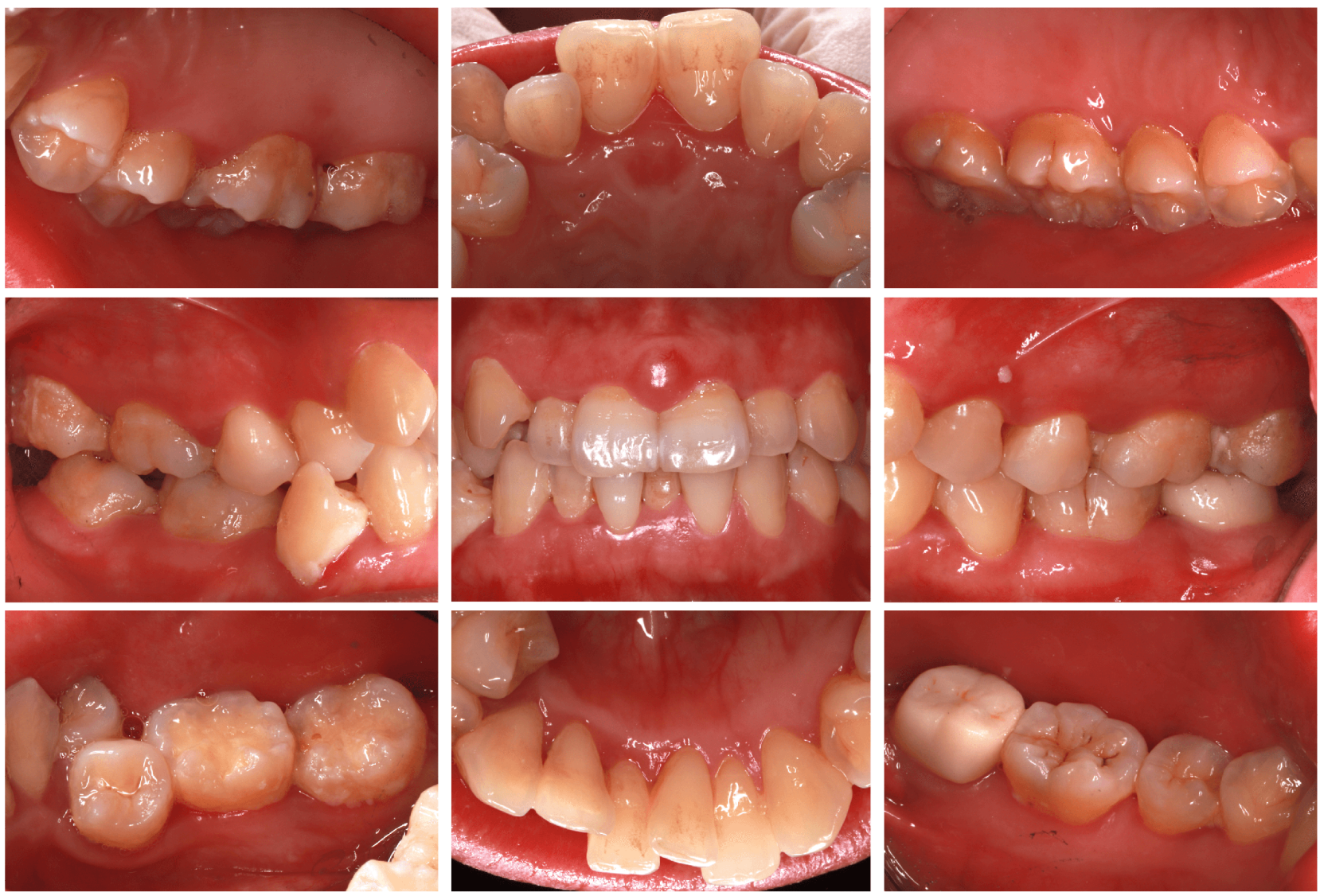

Figure 1 Intraoral photograph. At baseline, intraoral examination revealed a small, pink-colored, well-defined mass in the patient's labial gingival papilla between maxillary central incisor (teeth nos. 8 and 9).

pheochromocytomas (PCC) (1). MN of MEN 2B is always observed on the mucosal surfaces of the lips, tongue, eyelids, and intestines of patients (2), but rarely occur without the other abnormality about MEN 2B. Since 1986, solitary MN without MEN 2B have been reported in the rectosigmoid colon, bronchi, conjunctiva, laryngeal (3), tongue (4-6), lip and hard palate (7), and there has been no more than 8 cases in the oral cavity to our knowledge. In the vast majority of cases, complete surgical excision is curative; however, recurrences have been reported in some cases (5). Histologically, $\mathrm{MN}$ is characterized by irregular tortuous bundles of nerve cells with prominent perineurium that lie scattered throughout the submucosa (8).

Herein, we present a case of solitary $M N$ without MEN 2B occurs in the gingival papilla that has not been reported yet, in accordance with the CARE reporting checklist (available at https://fomm.amegroups.com/ article/vies/10.21037/fomm-20-80/rc) and review of relevant publications.

\section{Case presentation}

\section{Social and relevant medical and dental history}

A 29-year-old Asian female patient presented to the outpatient clinic of Department of Periodontology, Shanghai Ninth People's Hospital, Shanghai Jiao Tong University School of Medicine (Shanghai, China) with a 2 -year history of an upper anterior gingiva painless mass. She denied family history but did not undergo genetic testing. Her past medical history was noncontributory.

\section{Clinical findings}

Intraoral examination revealed a pink-colored, well-defined mass which is tough and basal wide in the labial gingival papilla between maxillary central incisor (teeth nos. 8 and 9) (Figure 1). At baseline, the patient had poor oral hygiene and gingiva was slightly red and swollen, plaque and calculus deposition, and a small amount of pigmentation 


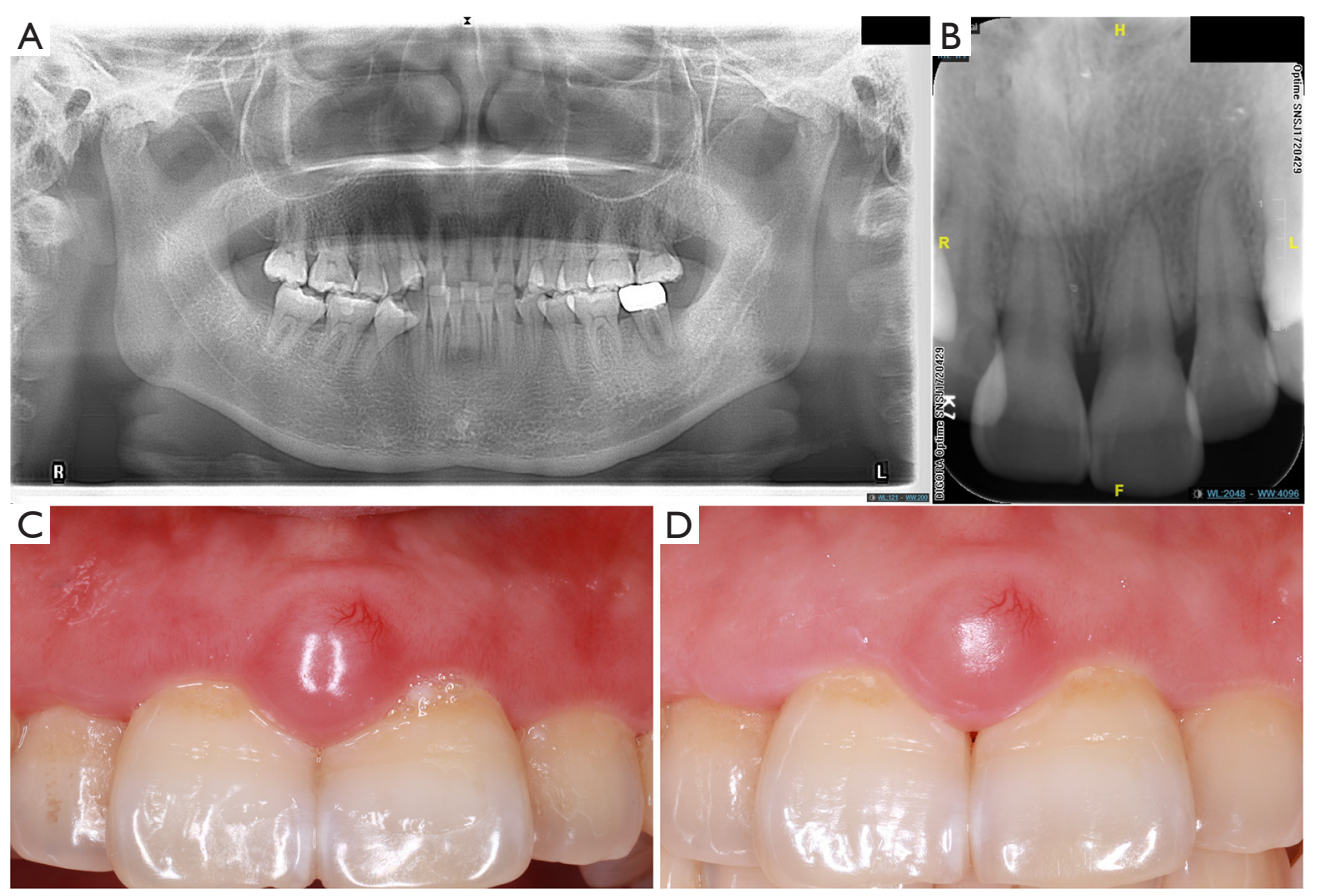

Figure 2 Radiographic examination and clinical photographs before and after periodontal initial therapy. Except for tooth no. 18, there were no obvious alveolar bone resorption and other abnormalities in the imaging performance of the remaining teeth. (A) Oral panoramic radiograph. (B) Digital periapical film. After periodontal initial therapy, there was no significant change in the size of the mass. (C) Base line. (D) After initial therapy.

was found on the tooth surface. A means probing depth (PD) of $2.83 \pm 1.02 \mathrm{~mm}$, means clinical attachment loss (CAL) of $1.18 \pm 0.68 \mathrm{~mm}$ and $73 \%$ of bleeding on probing (BOP).

\section{Radiological examination}

The patient underwent oral panoramic radiography and digital periapical film exam, and the results showed that there were no obvious abnormalities in the imaging performance of the remaining teeth except for tooth no. 18 (Figure 2A,B).

\section{Periodontal initial therapy}

The patient was informed that periodontal treatment was initiated via oral hygiene instructions and professional supragingival biofilm control, including supragingival and subgingival scaling, 4-6 weeks after periodontal initial therapy, the patient should be re-evaluation, including the mass size and periodontal clinical indexes. Six weeks after SRP, the re-evaluation clinical data showed a reduction in mean PD $(2.67 \pm 0.81 \mathrm{~mm})$ and a percentage of BOP $(20 \%)$.
There was no significant change in the size of the mass in the buccal gingival papilla between teeth nos. 8 and 9 (Figure 2C,D).

\section{Operation and laboratory examination}

After periodontal initial therapy, we performed an excisional biopsy of the mass. Examination of the biopsy specimen showed a $0.6 \mathrm{~cm} \times 0.6 \mathrm{~cm} \times 0.5 \mathrm{~cm}$, gray-white colored, well defined mucosal tissue. Histologically, nerve bundles in various sizes surrounded by normal connective tissue in the submucosa can be seen under HE staining, and nerve bundles are wrapped by thick perineurium (Figure 3). Immunohistochemically, the mass showed strongly positive staining of S-100 protein, neuron specific enolase (NSE), neurofilament protein (NFP) and weakly positive of epithelial membrane antigen (EMA) (Figure 4). Based on these features, the pathological diagnosis was $\mathrm{MN}$ of the maxillary incisor gingiva. 12 months later, the operation area heals well and there was no evidence of recurrence (Figure 3D). To rule out the possibility of MEN 2B, we did endocrinological examinations. The serum concentrations 

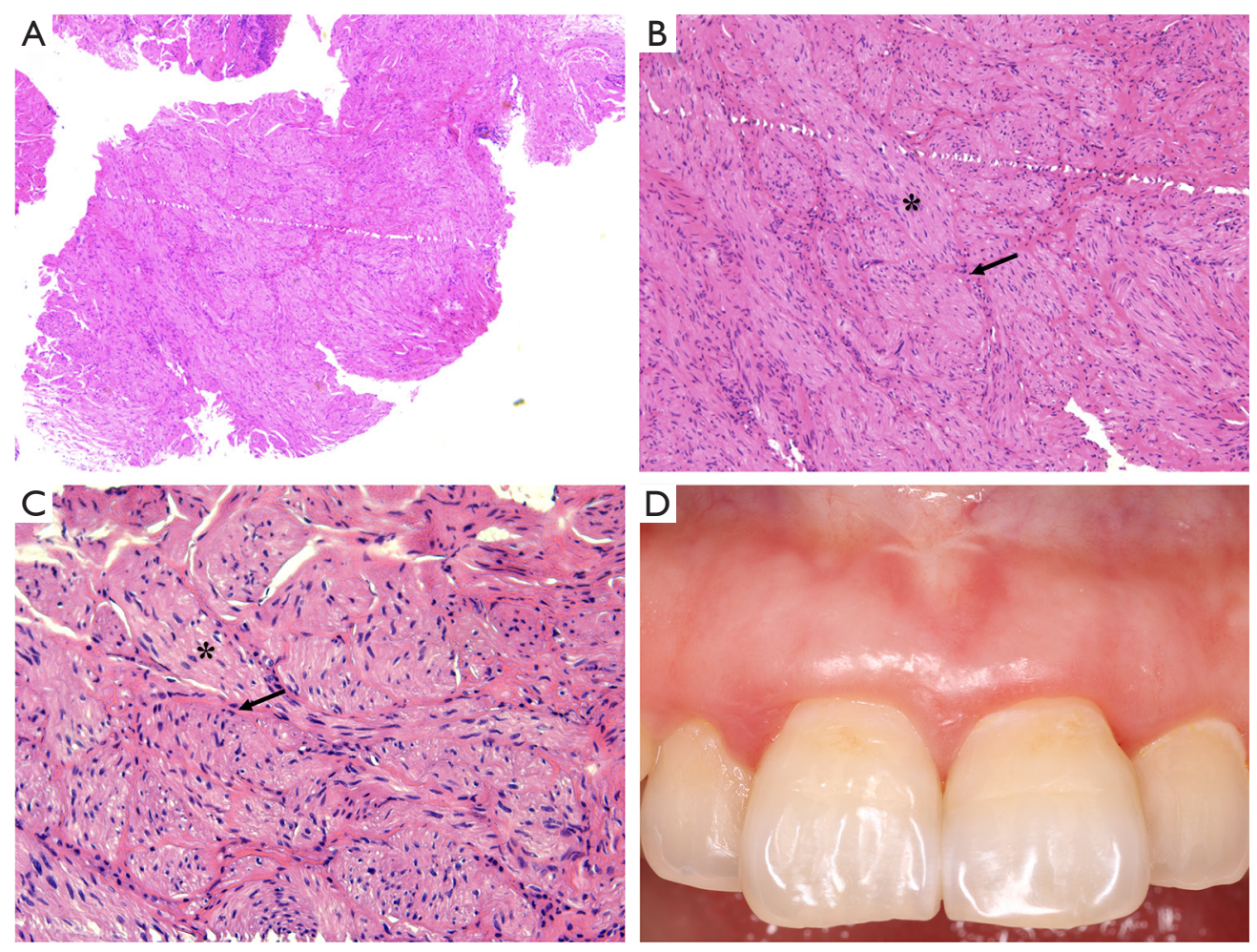

Figure 3 Histological hematoxylin and eosin photomicrographs. Histologically, irregular tortuous bundles of nerve cells (asterisks) with prominent perineurium (arrows) that lie scattered throughout the submucosa can be seen under HE staining (A,B,C). Magnification: $\times 50$ (A), $\times 100$ (B), $\times 200$ (C). 12 months after operation, the operation area heals well, and there was no evidence of recurrence (D).

of carcinoembryonic antigen, epinephrine, norepinephrine, dopamine, and calcitonin were all within normal limits. Ultrasonography of the thyroid gland was normal. These examinations showed no signs of MEN 2B. Finally, the lesion was clinically diagnosed as a solitary gingival $\mathrm{MN}$.

\section{Prognosis}

In the 12 months of follow-up, there was no evidence of recurrence and other components of MEN 2B. The patient was asymptomatic and she is still being followed up every 6 months. The Timeline of diagnosis, treatment and followup of this case are shown in Figure 5.

\section{Literature review}

According to the data reviewed, $\mathrm{MN}$ without MEN 2B have been reported less than 18 cases, and mere 8 cases have been reported in the oral cavity so far (Table 1) (3-7). No cases of $M N$ without MEN 2B in the gingiva have been reported. Furthermore, the patients with MN without MEN 2B were between 4 and 73 years of age and had no significant sex predilection. The preferred surgical treatment in the majority of cases was local excision, and 1 case of recurrence in the oral cavity have been reported (5). Additionally, all available data were reviewed, including epidemiology, clinical presentation, histopathologic examination findings, and surgical intervention.

\section{Ethics statement}

All procedures performed in studies involving human participants were in accordance with the ethical standards of the institutional and/or national research committee(s) and with the Helsinki Declaration (as revised in 2013). Written informed consent was obtained from the patient.

\section{Discussion}

Oral neurogenic tumors (ONTs) originate from cells associated with components of the peripheral nervous system. As an ONT, MN can be distinguished histologically 

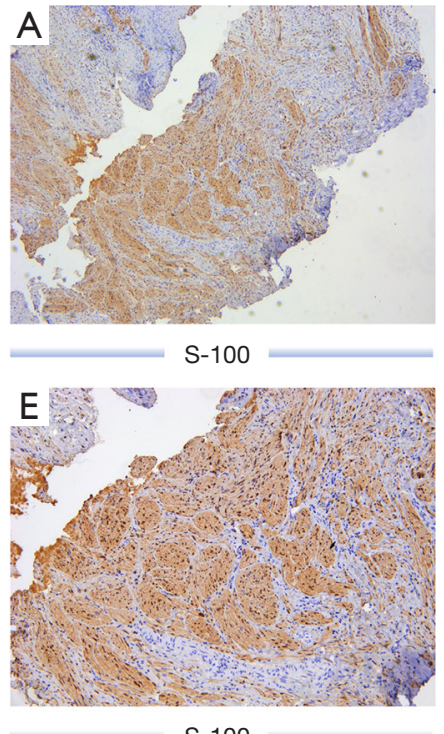

S-100

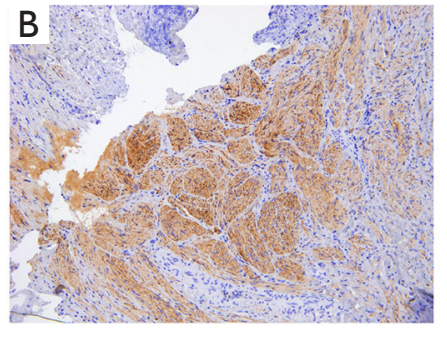

NSE

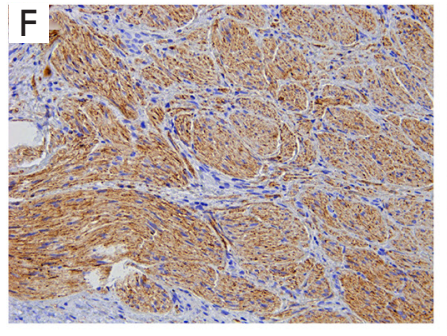

NSE

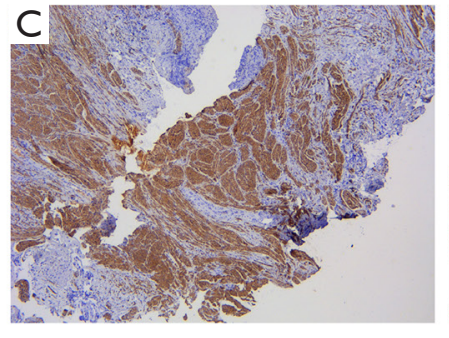

NF

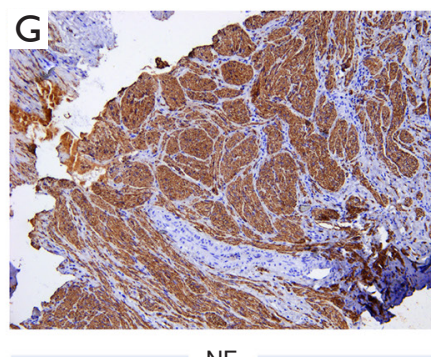

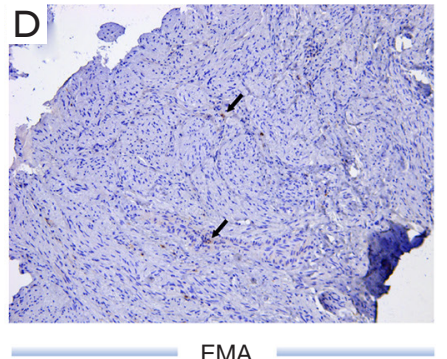

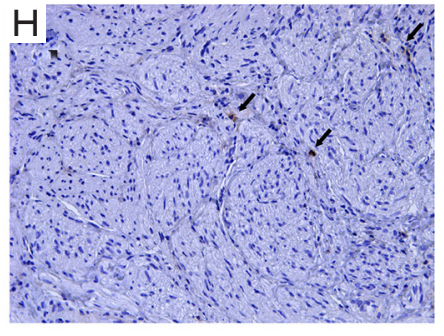

EMA

Figure 4 Images of immunohistochemical results of MN. Irregular tortuous bundles of nerve cells stain strongly positive of S-100 (A,E), NSE (B,F), NF (C,G) and perineurial cells stain weakly positive (arrows) of EMA (D,H). Magnification: $\times 50(A, C), \times 100(B, D, E, G)$, $\times 200(\mathrm{~F}, \mathrm{H})$.

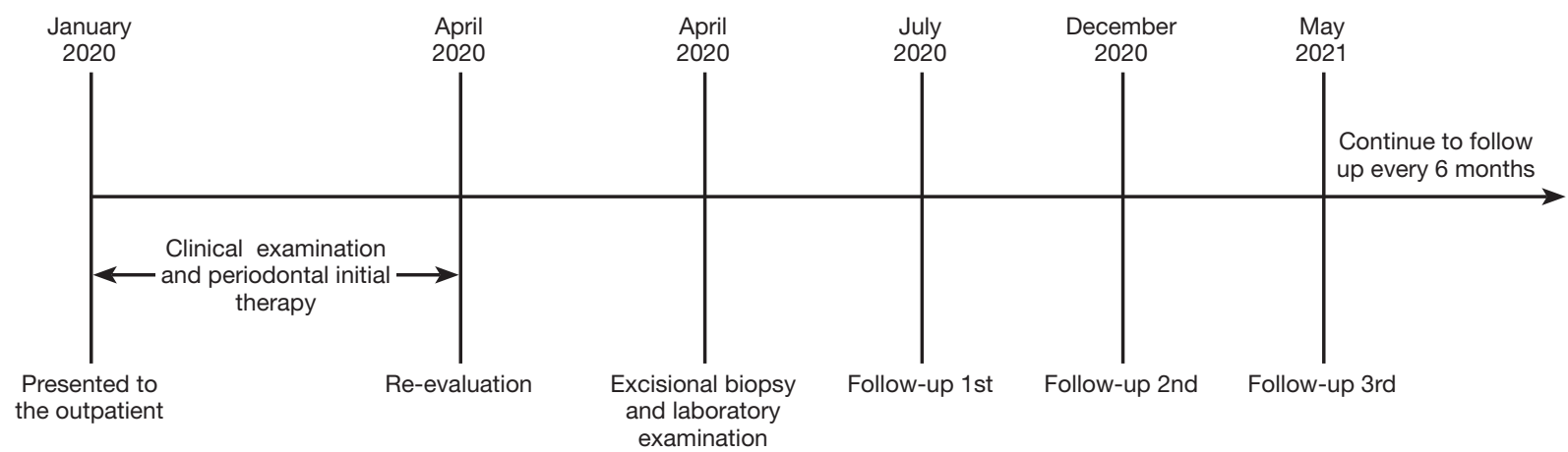

Figure 5 Timeline of diagnosis, treatment, and follow-up. The patient is still being followed up every 6 months.

from other ONTs such as neurofibroma, neurilemmoma and Palisaded encapsulated neuroma (PEN). Briefly, the microscopic examination of the MN shows nerve bundles in various sizes surrounded by normal connective tissue, and nerve bundles are wrapped by thick nerve bundle membrane, which is not usually seen in PENs (6), and the $\mathrm{MN}$ is not encapsulated and does not have palisading nuclei whereas neurilemomas and PENs are encapsulated (9).

Neurofibromas are not encapsulated and have no palisading, but neurilemmal cells and possibly fibroblasts participate in their formation, resulting in irregular combinations of these elements (10). However, plexiform neurofibromas (PN), atypical types of neurofibromas, may be confused with MNs, because both tumors have similar microscopic findings (11). Epithelial membrane antigen (EMA) is the most useful marker in differentiating $\mathrm{MN}$ from plexiform neurofibroma immunohistochemically. The perineurial cells of the former show the marker and tumor cells of the latter do not (11). Although the immunohistochemistry of our case showed weakly positive of EMA, almost all plexiform neurofibromas occurred in patients with neurofibromatosis type 1 (NF1). Furthermore, the microscopic examination of the plexiform neurofibroma usually shows enlarged nerve bundles and the interstitium 
Table 1 Summary of MN in the oral cavity without MEN 2B cases reported until 2019

\begin{tabular}{|c|c|c|c|c|c|c|c|}
\hline Reference & Country & $\begin{array}{l}\text { Patients } \\
\text { (n) }\end{array}$ & Location & Treatment & Diagnosis approach & Recurrence & Follow-up \\
\hline $\begin{array}{l}\text { Pujol et al. } \\
\text { (1997) }\end{array}$ & Spain & 1 & Tongue and lip & $\begin{array}{l}\text { Excisional } \\
\text { biopsy }\end{array}$ & $\begin{array}{l}\text { Histology, radiologic, biochemical, } \\
\text { and molecular genetic studies }\end{array}$ & None & 22 years \\
\hline $\begin{array}{l}\text { Mao et al. } \\
\text { (2011) }\end{array}$ & China & 3 & 2 throat and 1 tongue & $\begin{array}{l}\text { Excisional } \\
\text { biopsy }\end{array}$ & $\begin{array}{c}\text { Histology, IHC (S100, NFP and } \\
\text { NSE, positive, EMA, negative) and } \\
\text { radiologic studies }\end{array}$ & None & $6-20$ months \\
\hline $\begin{array}{l}\text { Gordon et al. } \\
(1998)\end{array}$ & UK & 4 & $\begin{array}{l}2 \text { tongues, } 1 \text { corner of the } \\
\text { mouth, } 1 \text { face (lip, eye, } \\
\text { nose, and buccal mucosa)* }\end{array}$ & $\begin{array}{l}\text { Excisional } \\
\text { biopsy }\end{array}$ & $\begin{array}{l}\text { Histology, radiologic, biochemical, } \\
\text { and molecular genetic studies }\end{array}$ & 1 & $3-10$ years \\
\hline
\end{tabular}

*, the patient who had facial neuromas recurred after each excision, extending along her left eye, nose, lips, and buccal mucosa. IHC, immunohistochemical; S100, S100 protein; EMA, epithelial membrane antigen; NFP, neurofilament protein; NSE, neuron specific enolase.

mostly mucoid, so the histological features of our case still resembled MN.

The proliferating nerve bundles express EMA, suggesting that the nerve bundles have differentiated to the perineurial cells (12), while no EMA-positive nerve bundle membrane may be due to the poor immunohistochemical technique or insufficient differentiation of the perineurial cells (3). In our case, the structure of the perineurium is obvious under the microscope, and EMA is positively expressed in the epithelial area, so we infer that the weakly positive reaction may be caused by insufficient differentiation of the perineurial cells.

MNs occur in the oral cavity, especially in the gingival papilla, which is also easy to be confused with other tumorlike lesions such as epulis (13). As a most common type of epulis, peripheral ossifying fibromas often show pinkcolored, tough, and well-defined mass the same as MNs. Peripheral ossifying fibromas can occur in all age groups but are more common in 10 to 40 years old. Histologically, peripheral ossifying fibromas usually show a stromal fibroblastic proliferation with intermixed hypermineralized bony tissue under HE staining, so we can differentiate MNs from peripheral ossifying fibromas.

MNs usually occur in the oral cavity as a component of MEN 2B, which is a syndrome of multiple MNs, MTC, pheochromocytoma (PCC), bumpy lips, and marfanoid habitus, although not always concurrently. MNs of MEN 2B may be present on the eyelids, conjunctiva, tongue, lip, intestinal tract, palate, pharyngeal and generally develops from early childhood with prominent "blubbery" lips, submucosal nodules on the vermilion border and MNs on the anterior dorsal surface of the tongue, etc. (14). Physical examinations may reveal an elongated face, lower jaw protrusion, large hands and feet and relatively long extremities (15). In addition, MTC commonly develops in all subtypes of MEN 2 and is the most important prognostic factor. Usually, MTC develops relatively young, exhibits a more aggressive disease course, and accounts for more than $95 \%$ of MEN 2B cases. MTC can be screened by thyroid function tests, thyroid ultrasonography, and biochemical tests (e.g., serum calcitonin).

MEN 2B is an autosomal dominant genetic disease caused mainly by Met918Thr germline RET mutation (16). After the diagnosis of MEN 2B, the patients' immediate family members should be screened for MTC and PCC, and early genetic testing for RET proto-oncogene mutations is necessary to achieve the purpose of early discovery and early treatment $(17,18)$. Therefore, MEN 2B can be diagnosed by the special face caused by MN, the clinical manifestations of MTC, PCC and radiography, biochemical examinations, and it can be diagnosed early by detecting mutations in RET proto-oncogene (19). Our patient showed no abnormalities in the skeletal structure, lip shape, sonographic examination of the thyroid, or in any of the endocrine examinations, and there were no tumors elsewhere in the oral cavity or the ocular region. 
$\mathrm{MN}$ occurs in different organs with different clinical manifestations. MN of the throat often causes hoarseness and prickly sensation in the throat, occasionally had a cough with sputa, but there is usually no pyrexia or dysphagia (3). Meanwhile, patients with MN of the bronchi often had a cough with sputa (20). MN present on intestinal tract often causes stomachache and constipation (21) and MNs of the oral cavity are usually painless but may interfere with eating or cause oral and maxillofacial deformities (4-7). Moreover, $\mathrm{MN}$ of the conjunctiva $\mathrm{MN}$ in the conjunctiva can cause foreign body sensation and dry eyes (22).

$\mathrm{MN}$ in the oral cavity without MEN 2B is very rare, a total of 9 cases have been reported including the case reported in this article. A solitary $\mathrm{MN}$ is present in the absence of other diagnostic signs, so it is necessary to combine the clinical examination, histopathological evaluation, IHC, radiography, and biochemical studies. Our patient was diagnosed as a solitary gingival $\mathrm{MN}$ without MEN 2B. Nevertheless, some investigators have suggested that MTC and PCC may appear later $(16,23)$. The knowledge of MEN 2B is still insufficient and the lack of knowledge impairs the ability to obtain an early diagnosis and cure. Thus, follow-up studies including radiography, endocrine examinations are necessary.

\section{Conclusions}

This study showed a rare $\mathrm{MN}$ in the gingiva papilla without MEN, the histopathological evaluation and immunoreaction of S-100 protein, EMA, NSE and NFP staining can be helpful in the differential diagnosis of $M N$. It is hoped that a greater understanding of MN without MEN in the oral cavity will avoid potential misdiagnosis, and contribute to determining the correct management, which appears to be complete surgical excision with close follow-up for recurrence and other components of MEN surveillance.

\section{Acknowledgments}

We thank Dr. Jingjing Sun from Department of Oral Pathology of Shanghai Ninth People's Hospital, Shanghai Jiao Tong University School of Medicine for his/her help in confirming the diagnosis.

Funding: This study was supported by grants from the Clinical Research Program of Shanghai Ninth People's Hospital, Shanghai Jiao Tong University School of Medicine (JYLJ038), Shanghai, China.

\section{Footnote}

Reporting Checklist: The authors have completed the CARE reporting checklist. Available at https://fomm.amegroups. com/article/view/10.21037/fomm-20-80/rc

Peer Review File: Available at https://fomm.amegroups.com/ article/view/10.21037/fomm-20-80/prf

Conflicts of Interest: All authors have completed the ICMJE uniform disclosure form (available at https://fomm. amegroups.com/article/view/10.21037/fomm-20-80/coif). The authors have no conflicts of interest to declare.

Etbical Statement: The authors are accountable for all aspects of the work in ensuring that questions related to the accuracy or integrity of any part of the work are appropriately investigated and resolved. All procedures performed in studies involving human participants were in accordance with the ethical standards of the institutional and/or national research committee(s) and with the Helsinki Declaration (as revised in 2013). Written informed consent was obtained from the patient.

Open Access Statement: This is an Open Access article distributed in accordance with the Creative Commons Attribution-NonCommercial-NoDerivs 4.0 International License (CC BY-NC-ND 4.0), which permits the noncommercial replication and distribution of the article with the strict proviso that no changes or edits are made and the original work is properly cited (including links to both the formal publication through the relevant DOI and the license). See: https://creativecommons.org/licenses/by-nc-nd/4.0/.

\section{References}

1. Owens M, Kivuva E, Quinn A, et al. SOS1 frameshift mutations cause pure mucosal neuroma syndrome, a clinical phenotype distinct from multiple endocrine neoplasia type 2B. Clin Endocrinol (Oxf) 2016;84:715-9.

2. Maymone MBC, Greer RO, Burdine LK, et al. Benign oral mucosal lesions: Clinical and pathological findings. J Am Acad Dermatol 2019;81:43-56.

3. Shimazaki T, Yoshida Y, Izumaru S, et al. Laryngeal solitary multiple mucosal neuromas without multiple endocrine neoplasia (MEN) type 2B. Auris Nasus Larynx 2003;30:191-5.

4. Gómez JM, Biarnés J, Volpini V, et al. Neuromas and 
prominent corneal nerves without MEN 2B. Ann Endocrinol (Paris) 1998;59:492-4.

5. Gordon Cm, Majzoub JA, Marsh DJ, et al. Four cases of mucosal neuroma syndrome: multiple endocrine neoplasm 2B or not 2B? J Clin Endocrinol Metab 1998;83:17-20.

6. Mao RJ, Zhong YP, Peng GG, et al. Clinicopathological features of multiple mucosal neuroma without multiple endocrine neoplasia type IIB. Zhonghua Er Bi Yan Hou Tou Jing Wai Ke Za Zhi 2011;46:681-3.

7. Nishihara K, Yoshida H, Onizawa K, et al. Solitary mucosal neuroma of the hard palate: a case report. $\mathrm{Br} \mathrm{J}$ Oral Maxillofac Surg 2004;42:457-9.

8. Dhanuka S, Rodrigues G, Carnello S. Ulcerated bleeding palisaded encapsulated neuroma of the tongue. Malays J Pathol 2019;41:229-32.

9. Koutlas IG, Scheithauer BW. Palisaded encapsulated ("solitary circumscribed") neuroma of the oral cavity: a review of 55 cases. Head Neck Pathol 2010;4:15-26.

10. Atarbashi-Moghadam S, Lotfi A, Salehi Zalani S, et al. Palisaded Encapsulated (Solitary Circumscribed) Neuroma of the Buccal Mucosa: a Rare Case. J Dent (Shiraz) 2017;18:314-7.

11. Cangiarella J, Jagirdar J, Adelman H, et al. Mucosal neuromas and plexiform neurofibromas: an immunocytochemical study. Pediatr Pathol 1993;13:281-8.

12. Gnepp DR. Diagnostic Surgical Pathology of The Head and Neck. Philadelphia: WB Saunders Company, 2000:194-5.

13. Truschnegg A, Acham S, Kiefer BA, et al. Epulis: a study of 92 cases with special emphasis on histopathological diagnosis and associated clinical data. Clin Oral Investig 2016;20:1757-64.

14. Morrison PJ, Nevin NC. Multiple endocrine neoplasia type 2B (mucosal neuroma syndrome, Wagenmann-

doi: 10.21037/fomm-20-80

Cite this article as: Qiu C, Wang L, Chen H, Song Z. Solitary mucosal neuroma of the gingiva without multiple endocrine neoplasia type 2B: a rare case report and literature review. Front Oral Maxillofac Med 2021;3:39.
Froboese syndrome). J Med Genet 1996;33:779-82.

15. Lee MJ, Chung KH, Park JS, et al. Multiple Endocrine Neoplasia Type 2B: Early Diagnosis by Multiple Mucosal Neuroma and Its DNA Analysis. Ann Dermatol 2010;22:452-5.

16. Castinetti F, Waguespack SG, Machens A, et al. Natural history, treatment, and long-term follow up of patients with multiple endocrine neoplasia type $2 \mathrm{~B}$ : an international, multicentre, retrospective study. Lancet Diabetes Endocrinol 2019;7:213-20.

17. Prete FP, Abdel-Aziz T, Morkane C, et al. Prophylactic thyroidectomy in children with multiple endocrine neoplasia type 2. Br J Surg 2018;105:1319-27.

18. Qi XP, Zhao JQ, Du ZF, et al. Prophylactic thyroidectomy for MEN 2-related medullary thyroid carcinoma based on predictive testing for RET proto-oncogene mutation and basal serum calcitonin in China. Eur J Surg Oncol 2013;39:1007-12.

19. Scott AR, Compton RA. Mucosal Neuromas. N Engl J Med 2019;381:e5.

20. Erdem I, Duman D, Eroglu S, et al. Endobronchial Mucosal Neuroma with Sarcoidosis. J Coll Physicians Surg Pak 2018;28:162-3.

21. Attar B, Khurana D, Hlaing-Ray V, et al. Mucosal neuroma of the rectosigmoid colon. Gastrointest Endosc 1986;32:219-20.

22. Higashide $Y$, Nemoto $Y$, Imamura T. A case of conjunctival mucosal neuroma without multiple endocrine neoplasia. Nippon Ganka Gakkai Zasshi 1997;101:621-5.

23. Elisei R, Matrone A, Valerio L, et al. Fifty Years After the First Description, MEN 2B Syndrome Diagnosis Is Still Late: Descriptions of Two Recent Cases. J Clin Endocrinol Metab 2019;104:2520-6. 